\title{
Por dentro do computador: trajetória de um projeto extensionista em um Campus da UFPR no interior do Paraná
}

\author{
Carlos R. Beleti Junior ${ }^{1}$, Robertino M. Santiago Junior ${ }^{1}$, Alexandre P. Züge ${ }^{1}$, \\ Marcelo Valério ${ }^{1}$, Maytê G. C. Bezerra ${ }^{1}$ \\ ${ }^{1}$ Câmpus Avançado Jandaia do Sul - Universidade Federal do Paraná \\ Avenida Doutor João Maximiano, 426 - Vila Operaria - Jandaia do Sul - 86900-000 \\ \{carlosbeleti, robertino, alexandrezuge, marcelovalerio, mayte\}@ufpr.br
}

\begin{abstract}
This article reports the conception and activities of an extension project born in 2014 on a campus at the Federal University of Paraná in the interior of the state. The project originated from the lack of initiatives to divulgation and popularization science and technology in the city of Jandaia do Sul and in the Vale do Ivaí. Since its inception, approximately 22,000 people (physically) have been reached, 6500 video views, 830 followers and 500 subscribers through their social networks, 18 schools, colleges and community institutions in addition to two regional education centers. Its team included 30 students from the five undergraduate courses at the campus, including volunteers and scholarship holders, and 11 professors.
\end{abstract}

Resumo. Este artigo relata a concepção e as atividades de um projeto de extensão nascido em 2014 em um câmpus da Universidade Federal do Paraná no interior do estado. O projeto originou-se da carência de iniciativas de divulgação e popularização de ciência e tecnologia na cidade de Jandaia do Sul e no Vale do Ivaí. Desde seu início, foram alcançadas aproximadamente 22000 pessoas (fisicamente), 6500 visualizações em vídeos, 830 seguidores e 500 inscritos por meio de suas redes sociais, 18 escolas, colégios e instituições comunitárias além de dois núcleos regionais de educação. Fizeram parte de sua equipe 30 estudantes dos cinco cursos de graduação do câmpus, entre voluntários e bolsistas, e 11 professores.

\section{Introdução}

"Por dentro do computador: uma experiência de popularização da Arquitetura de Computadores" é um projeto de divulgação e popularização da ciência e da tecnologia, institucionalizado como ação de Extensão Universitária do câmpus avançado Jandaia do Sul da Universidade Federal do Paraná (UFPR). O presente trabalho relata a concepção e as atividades deste projeto.

Localizada entre os dois grandes centros urbanos e acadêmicos, Maringá e Londrina, no centro norte do estado do Paraná, a cidade de Jandaia do Sul possui cerca de 20.000 habitantes e centraliza uma região identificada como Vale do Ivaí [IBGE 2020]. Foi nesta cidade que, em 2014, a UFPR promoveu sua interiorização e se instalou com a oferta de cinco cursos de graduação: Engenharia Agrícola, Engenharia de Alimentos, Engenharia de Produção, Licenciatura em Ciências Exatas e Licenciatura em Computação. 
No início das atividades, o câmpus contava com 11 docentes, 10 servidores técnicoadministrativos e recebia 119 estudantes.

A estrutura incipiente e a inexperiência de parte da equipe de servidores, muitos dos quais iniciavam suas trajetórias no ensino superior, não impediu que a instituição reconhecesse as demandas do entorno e buscasse, logo, respondê-las. Nesse processo, uma das constatações foi a carência de espaços e ações culturais que estivessem, em alguma medida, relacionadas à ciência e à tecnologia. Assim, compreendendo o sentido da Extensão como atividade-fim da universidade, e o potencial da divulgação científica e tecnológica como iniciativa cultural, começava a ser concebido o projeto em tela.

O objetivo que gestou o "Por dentro do Computador" foi popularizar e difundir conhecimentos básicos, relacionados às máquinas computacionais de uso diário (computadores, tablets e smartphones), para públicos não iniciados. Como justificativa, apresentava-se a possibilidade de contribuir com a formação educativa comunitária, vislumbrando o exercício pleno da cidadania, que sugere familiaridade e conhecimentos relacionados à tecnologia sem a necessidade de acesso à especialistas.

\section{Atividades e ações desenvolvidas}

Concebido como ação de Extensão Universitária, o "Por dentro do Computador" nasceu como uma atividade de relacionamento universidade-comunidade, buscando pôr em diálogo as práticas e os saberes acadêmicos com a cultura popular. Não possuía pretensões sistemáticas, hierárquicas ou de institucionalização de seus processos, de modo a se caracterizar como uma iniciativa de educação não-formal [Gohn 2010, Gadotti 2005]. Ainda nesses termos, empreendendo um esforço de popularização da Tecnologia e da Computação, conceituou-se como um conjunto de ações de divulgação científica - nos termos com que a expressão vem se consolidando na literatura no Brasil [Marandino et al. 2004].

Visando acessar/atingir o maior número de pessoas, garantindo que todas pudessem participar e compreender os conceitos propostos, a principal produção do projeto foi um diorama (Figura 1(a)). O diorama é um cenário construído com a finalidade de simular ambientes reais [Ash 2004, Marandino and Laurini 2018]. O diorama construído para o projeto é uma representação dos componentes de uma máquina computacional, produzido em escala aumentada, com a finalidade de despertar o interesse dos visitantes em participar das atividades e então aprender de maneira diferenciada [Alves et al. 2019].

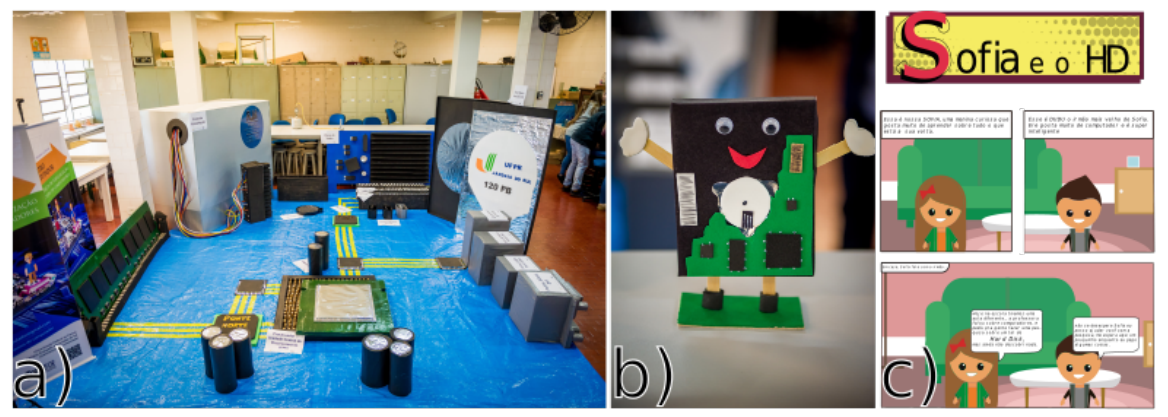

Figura 1. Produções do projeto - a) Diorama; b) Boneco didático; c) História em quadrinho 
Outros materiais foram e vêm sendo desenvolvidos, como os bonecos didáticos (Figura 1(b)), os quais são representações de componentes de máquinas computacionais produzidos em forma de boneco e visam possibilitar que os participantes das atividades, ao levar para casa ao menos um dos bonecos, disseminem de modo despretensioso os conceitos discutidos durante a atividade.

Durante nossas intervenções, têm se mostrado efetivo o uso de sistemas de resposta à audiência junto à jogos de perguntas e respostas, em que o público participa ativamente, em tempo real, respondendo questões relacionadas ao componentes de uma máquina computacional. Este recurso tem permitido avaliar as atividades realizadas, mensurando o entendimento do público participante.

Outra produção são as histórias em quadrinho, através das quais busca-se atingir um público mais infantil. A primeira história produzida conta a história do HD (Figura 1(c)) e segue em curso a produção de contos sobre os demais componentes de uma máquina computacional visando a criação de uma coletânea completa.

Dois recursos amplamente utilizados para divulgações em mídias sociais são os vídeos (Figura 2(a)) e animações (Figura 2(b)), ambas relacionadas aos conhecimentos sobre Computação e conceitos de componentes computacionais. Os vídeos são voltados para públicos com faixa etária maior que 14 anos e as animações destinadas às crianças. Os vídeos e animações podem ser encontrados no canal do projeto no Youtube ${ }^{1}$.

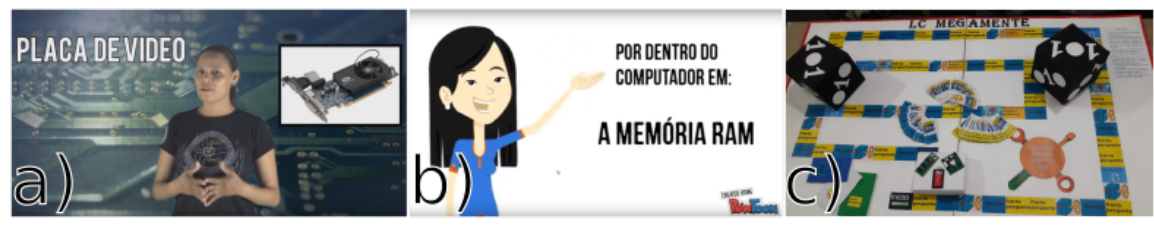

Figura 2. Produções do projeto - a) Vídeo; b) Animação; c) Jogo didático

Ainda para o público em idade escolar, são produzidos jogos e atividades lúdicas, sendo um tabuleiro (Figura 2(c)) e uma cartela de bingo binário (Figura 3(a)). No tabuleiro, cada casa representa um desafio ou pergunta que o participante deve responder ou completar para prosseguir. O bingo binário é utilizado para mostrar aos participantes, de maneira não formal, que existem sistemas de numeração distintos do decimal, por exemplo, o binário.
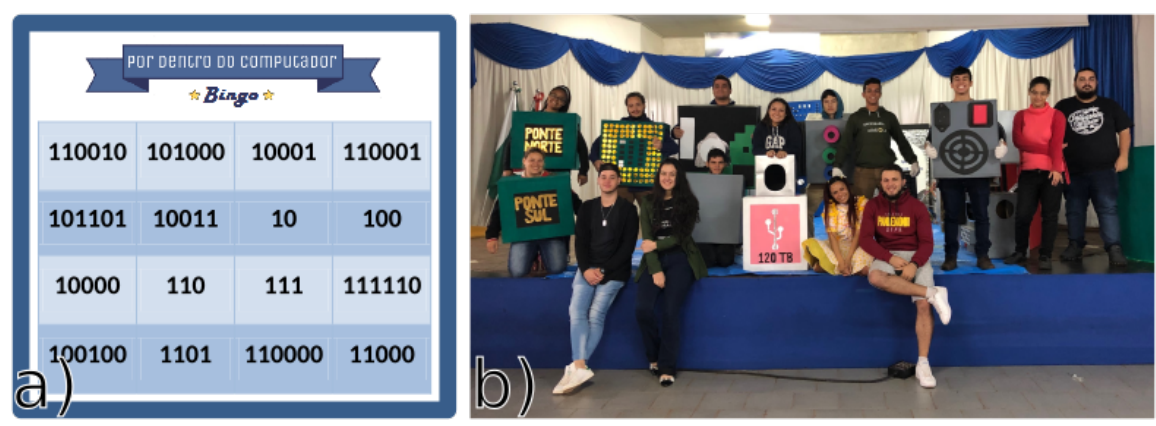

Figura 3. Produções do projeto - a) Bingo binário; b) Atores da peça teatral

\footnotetext{
${ }^{1} \mathrm{http} / / / \mathrm{www}$. youtube.com/pordentrodocomputador
} 
Outra atividade que surgiu em 2019, protagonizada pelos estudantes do projeto foi uma peça teatral (Figura 3(b)). Essa, intitulada "Sofia no mundo dos computadores", narra a história de uma menina que precisa compreender conceitos computacionais e pede ajuda para seu irmão mais velho, o qual leva-a para dentro do "computador gigante" com componentes que falam e andam, descobrindo assim como funciona um computador.

Além do canal no Youtube, outros meios têm sido utilizados para levar as ações e atividades do projeto para públicos que não têm contato físico em Jandaia do Sul e região. Página institucional ${ }^{2}$ do projeto, página do Facebook $^{3}$ e perfil no Instagram $^{4}$ tem auxiliado nessa tarefa. Outro recurso fundamental de divulgação do projeto é a página da chancela ${ }^{5}$ do projeto no site da Sociedade Brasileira da Computação, principal organização da área da Computação no país.

\section{Alcance, limitações e dificuldades}

Até o momento, o projeto alcançou aproximadamente 22.000 pessoas (fisicamente) por meio de suas atividades, ações e participação de grandes eventos, seminários, congressos, feiras, entre outros. Obteve mais de 6500 visualizações em vídeos, contando atualmente com 830 seguidores e 500 inscrições por meio de suas redes sociais. Tem como parceiros e apoiadores 18 escolas e colégios, além de instituições comunitárias e dois núcleos regionais de educação (Apucarana e Maringá).

Fizeram parte de sua equipe executora 30 estudantes dos cinco cursos de graduação do câmpus, entre voluntários e bolsistas, oferecendo 38 bolsas de auxílio financeiro distribuídas pelos 6 anos de realização do projeto, além de 11 professores da instituição. Além de atividades de extensão, uma orientação de trabalho de conclusão de curso foi realizada com a temática e produção de material didático relacionados ao projeto. Ademais, foram realizadas diversas publicações e participações em eventos nacionais, regionais e locais.

Como forma de fortalecer a divulgação e popularização da ciência e tecnologia, parcerias foram estabelecidas entre o projeto e outras instituições públicas de ensino superior, entre elas a Universidade Estadual de Maringá, por meio do Projeto Manna ${ }^{6}$ e o câmpus Maracanaú do Instituto Federal de Educação, Ciência e Tecnologia do Ceará, eixo de Computação e Departamento de Extensão. Neste último, um diorama foi produzido sobre a tutoria dos membros do projeto.

Apesar dos materiais desenvolvido, das atividades e ações realizadas, já descritos no decorrer deste trabalho, somente em 2020 o projeto foi contemplado com um edital de apoio financeiro e dessa forma, todo a matéria-prima utilizada na produção dos materiais havia sido financiada pelos professores coordenadores e orientadores do projeto.

O diorama carece de um espaço para exposição ao público, quanto em intervenções realizadas na própria UFPR. Tal necessidade recentemente foi contemplada, com a designação de uma sala própria, mas infelizmente não há garantias de sua manutenção dada a frequente necessidade de revisão de uso dos espaços no câmpus.

\footnotetext{
${ }^{2}$ http://www.jandaiadosul.ufpr.br/extensao/por-dentro-do-computador

${ }^{3}$ https://www.facebook.com/pordentrodocomputador

${ }^{4}$ https://www.instagram.com/pordentrodocomputador

${ }^{5}$ http://www.sbc.org.br/institucional-3/chancela-sbc/por-dentro-do-computador

${ }^{6}$ https://pt-br.facebook.com/mannateam
} 
Também vale nota, a dificuldade de transporte dos componentes do diorama para intervenções em outros espaços, pois o carro da universidade disponível, não dispõe de carroceria coberta, restando ao transporte estar sujeito às boas condições climáticas.

\section{Considerações finais}

O presente trabalho apresentou, de maneira sucinta, o relato de experiência do projeto de extensão "Por dentro do computador: uma experiência de popularização da Arquitetura de Computadores", iniciado em 2014 no câmpus avançado da Universidade Federal do Paraná em Jandaia do Sul.

Durante esses anos, mais de 22 mil pessoas foram alcançadas com as atividades do projeto, seja presencialmente ou virtualmente. O projeto recebeu destaque nacional ao receber a Chancela da Sociedade Brasileira de Computação, demonstrando o caráter inovador das ações realizadas.

Além disso, o projeto pode contribuir com a formação, tanto profissional quanto pessoal, dos estudantes vinculados. Profissionalmente, quando estes estudantes desenvolvem atividades relacionadas ao uso de tecnologias, adquirem competências primordiais para as diversas áreas de atuação. Ademais, as atividades desenvolvidas favorecem o surgimento/aprimoramento de outras competências, como a oratória, didática e relacionamento interpessoal. No tocante da formação pessoal, ao participar das atividades, os estudantes são inseridos no cotidiano da comunidade, vivenciando realidades culturais e econômicas muitas vezes fragilizadas, levando-os a compreender a importância de suas ações na melhoria da própria comunidade.

\section{Referências}

Alves, G. J., Gonçalves, D. C. M., Züge, A. P., Beleti Junior, C. R., and Santiago Junior, R. M. (2019). Por dentro do computador: uma iniciativa de divulgação e popularização da arquitetura de computadores, chapter 15, pages 162-172. Booknando Livros, Palotina.

Ash, D. (2004). How families use questions at dioramas: Ideas for exhibit design. Curator: The Museum Journal, 47(1):84-100.

Gadotti, M. (2005). A questão da educação formal/não-formal. Sion: Institut Internacional des Droits de $1^{\circ}$ Enfant, pages 1-11.

Gohn, M. G. (2010). Educação não formal e o educador social: atuação no desenvolvimento de projetos sociais. Questões da nossa época. Cortez, São Paulo.

IBGE (2020). Instituto Brasileiro de Geografia e Estatística. Censo demográfico 2010. https://cidades.ibge.gov.br/brasil/pr/jandaia-do-sul/panorama. Acesso em: 03 março 2020.

Marandino, M. and Laurini, C. (2018). A compreensão da biodiversidade por meio dioramas de museus de zoologia: um estudo com público adulto no brasil e na dinamarca. Ensaio Pesquisa em Educação em Ciências (Belo Horizonte), 20.

Marandino, M., Silveira, R. V. M., Chelini, M. J., Fernandes, A. B., Rachid, V., Martins, L. C., Lourenço, M. F., Fernandes, J. A., and Florentino, H. A. (2004). A educação não formal e a divulgação científica: o que pensa quem faz? In Encontro Nacional de Pesquisa em Ensino de Ciências - ENPEC. 